This article was published as Mouhamed Ndong et al. Estimating the risk of cyanobacterial occurrence using an index integrating meteorological factors: Application to drinking water production. Water Research, 2014, 56, 98-108. DOI:10.1016/j.watres.2014.02.023

\title{
Estimating the risk of cyanobacterial occurrence using an index integrating meteorological factors: application to drinking water production
}

Mouhamed Ndong ${ }^{1}$, ${ }^{*}$, David Bird ${ }^{2}$, Tri Nguyen-Quang ${ }^{3}$, Marie-Laure de Boutray ${ }^{1}$, Arash Zamyadi ${ }^{1}$, Brigitte Vinçon-Leite ${ }^{4}$, Bruno J. Lemaire ${ }^{4,5}$, Michèle Prévost $^{1}$, Sarah Dorner ${ }^{1}$

\footnotetext{
${ }^{1}$ École Polytechnique de Montreal, Civil, Mineral and Mining Engineering Department, P.O. Box 6079, Station Centre-ville, Montreal, Quebec, Canada, H3C 3A7

${ }^{2}$ Department of Biological Sciences, Université du Québec à Montréal, C.P. 8888, succ. Centre-ville, Montréal (Québec), Canada, H3C 3P8

${ }^{3}$ Department of Engineering, Faculty of Agriculture, Dalhousie University, PO Box 550, Truro-Bible Hill (Nova Scotia), Canada, B2N 5E3

${ }^{4}$ LEESU, Ecole des Ponts ParisTech, Université Paris-Est, 6 et 8 avenue Blaise Pascal, Cité Descartes, 77455 Marne la Vallée Cedex 2. France

${ }^{5}$ AgroParisTech, 16 rue Claude Bernard, 75005 Paris, France
}

\begin{abstract}
The sudden appearance of toxic cyanobacteria (CB) blooms is still largely unpredictable in waters worldwide. Many post-hoc explanations for CB bloom occurrence relating to physical and biochemical conditions in lakes have been developed. As potentially toxic CB can accumulate in drinking water treatment plants and disrupt water treatment, there is a need for water treatment operators to determine whether conditions are favourable for the proliferation and accumulation of $\mathrm{CB}$ in source waters in order to adjust drinking water treatment accordingly. Thus, a new methodology with locally adaptable variables is proposed in order to have a single index, $f(p)$, related to various environmental factors such as temperature, wind speed and direction. The index is used in conjunction with real time monitoring data to determine the probability of $C B$ occurrence in relation to meteorological factors, and was tested at a drinking water intake in Missisquoi Bay, a shallow transboundary bay in Lake Champlain, Québec, Canada. These environmental factors alone were able to explain a maximum probability of $68 \%$ that a CB bloom would occur at the drinking water treatment plant. Nutrient limitation also influences CB blooms and intense blooms only occurred when the dissolved inorganic nitrogen (DIN) to total phosphorus (TP) mass ratio was below 3. Additional monitoring of DIN and TP could be considered for these source waters prone to cyanobacterial blooms to determine periods of favourable growth. Real time monitoring and the use of the index could permit an adequate and timely response to CB blooms in drinking water sources.
\end{abstract}

Keywords: cyanobacteria, meteorological index, drinking water intake, early warning systems, wind, nutrient mass ratios

* Corresponding author E-mail: mouhamed.ndong@polymtl.ca 


\section{Introduction}

Harmful cyanobacteria (CB) blooms have been noted worldwide. CB blooms may release toxins, which can be harmful for aquatic communities (Bartram and Chorus, 1999), limit recreational and economic activities (Steffensen, 2008) and constitute a threat to drinking water sources (Zamyadi et al., 2012a). Long-term solutions for restoring water bodies require an understanding of the factors that are contributing to the increase of CB blooms (Wongsai and Luo, 2007). Thus, considerable efforts have been made globally in order to understand the environmental factors related to these phenomena for better management of the affected water bodies (Trojanowska and Izydorczyk, 2010, Le Vu et al., 2010; Falconer, 2005). Both endogenous factors (e.g. nutrients, water temperature) and exogenous factors (air temperature, solar radiation, wind speed and wind direction) can be considered to play a role in CB bloom development (Howard, 1994). Short term fluctuations of meteorological variables play an important role with regards to CB occurrence (Wu et al. 2013).

Generally, the principal focus of past studies has been on the effects of nutrients. Thus, the mass ratio (TN/TP) of total nitrogen (TN) to total phosphorus (TP) in water and in biomass has been studied as an index for its relationship to CB blooms (Lilover and Stips, 2008; Havens et al., 2003; Smith, 1986; Schindler, 1977). However, others have had concerns (Ferber et al., 2004) or do not support the use of TN/TP mass ratio (Jayatissa et al., 2006). It has been suggested that eutrophication generated by phosphorus is the main cause of CB blooms (Christian et al., 1988), but this view has been qualified of overly simplistic and is not applicable to all water bodies (e.g. Vincent, 1981). Thus, the TN/TP mass ratio is not the only indicator to predict CB blooms and a consensus does not exist with regards to a quantitative value. Another approach related to the mass ratio of Dissolved Inorganic Nitrogen (DIN) to total phosphorus (TP) has also been proposed and was shown to be a better predictor of CB biomass than the TN/TP mass ratio with $C B$ bloom occurrences observed when the DIN/TP mass ratio was below 2 (Bergstrom, 2010; Ptacnik et al., 2010).

In addition to nutrients, meteorological conditions are required to explain CB bloom occurrences. Meteorological variables are known to have a significant influence on CB development (Elliott, 2012; Reichwaldt and Ghadouani, 2012; Liu et al., 2012a). Many authors have explored the relationships among meteorological variables and CB (e.g. Lilover and Stips, 2008; Bormans et al, 2005; Kanoshina et al., 2003; Liu et al., 2012a; Liu et al., 2012b). Various weather variables have been related to CB blooms such as air temperature (Elliott, 2012; Reichwaldt and Ghadouani, 2012; Zhang et al., 2012), rainfall (Reichwaldt and Ghadouani, 2012), wind (Liu et al., 2012a; Liu et al., 2012b; Zhang et al., 2012) and sunshine hours (Zhang et al., 2012). Wind in particular may play both direct and indirect roles in determining cyanobacterial densities (Falconer et al., 1999). Wind can generate complex physical processes, such as internal waves or seiches, which produce periodic motion of the water layers in stratified lakes (e.g. Lemmin and Mortimer, 1986). These internal waves affect the spatial distribution of phytoplankton in the epilimnetic layer (Marcé et al., 2007). In deep lakes, they have a great impact on the distribution of cyanobacteria proliferating in the metalimnion and on their growth though a direct influence on light availability (Cuypers et al., 2011). As CB are buoyant, wind can result in accumulation of cyanobacteria at specific locations 
during a bloom (Cao et al., 2006; Ostos et al., 2009; Kanoshina et al., 2003), but it may also indirectly influence nutrient availability through mixing processes of the water column (e.g. Maclntyre et al., 1999; Livingstone, 2003; Schmittner, 2005).

Other meteorological variables such as the relative humidity, minimum daily air temperature and the amount of solar radiation (sunspots) have also been related to CB density (Hu et al., 2009). It has been hypothesized that the increase in the number of $\mathrm{CB}$ blooms is at least partly related to global climate change and increasing air temperatures (Zhang et al., 2012; Wagner and Adrian, 2009; Mooij et al, 2007). Although the effect of water temperature on growth is species-specific (Mehnert et al., 2010) some generalizations can be made for the CB native to temperate environments. Seaburg et al. (1981) found that the majority of CB have an optimal growth temperature of $25^{\circ} \mathrm{C}$. However, many bloom forming $\mathrm{CB}$ show optimal growth rates at temperatures of $25^{\circ} \mathrm{C}$ or higher (Robarts and Zohary, 1987). Tang et al. (1997), in studying the predominance of CB in freshwater in polar environments, showed that the growth was undetectable when the temperature of the aquatic environment in which the $\mathrm{CB}$ live was less than or equal to $5^{\circ} \mathrm{C}$ or greater than $35^{\circ} \mathrm{C}$.

Consideration of meteorological variables is important when implementing an early warning system for the proliferation of $\mathrm{CB}$ in drinking water sources (Hu et al., 2009). In the United States, NOAA issues weekly harmful algal bloom reports based upon satellite imagery and meteorological conditions (Wynne et al., 2013). Early warning systems are needed for drinking water treatment plant operators who must adjust treatment according to the biovolume and species of CB present, including such measures as changing coagulant, or adjusting the doses of treatment chemicals to be added (Zamyadi et al., 2013). For drinking water treatment, in sources highly impacted by cyanobacteria, operational decisions must be made in real time. Thus, weekly forecasts can provide useful information, but higher resolution forecasts are required (i.e. daily or sub-daily).

For the development of a reliable index which can serve as a 'universal threshold' for the occurrence of $\mathrm{CB}$ blooms in the aquatic environment, the effects of endogenous factors and exogenous parameters must be investigated. It is anticipated that the threshold for CB bloom occurrence will be based on the coupled effects of these external and internal factors. Thus, the objectives of this study are to: (1) through a new approach, propose an index in the form of a unique factor that integrates the effects of exogenous factors such as meteorological variables and water temperature on $\mathrm{CB}$ occurrence at a drinking water treatment plant intake, (2) evaluate this index to determine the probability of CB occurrence as an aid to operational decision making for water treatment plants, and (3) assess the role of nutrient limitation and the DIN/TP mass ratio as additional variables to be monitored along with phycocyanin at drinking water intakes. This paper proposes a novel index approach integrating meteorological factors and continuous phycocyanin probe measurements to determine drinking water intake risk as a result of intense cyanobacterial blooms. 


\section{Methodology}

\subsection{Site description}

The research was performed at Missisquoi Bay, a large bay $\left(77.5 \mathrm{~km}^{2}\right.$ at the latitude and longitude coordinates of $45^{\circ} 01^{\prime} 37.63^{\prime \prime}$ North and $-73^{\circ} 07^{\prime} 34.84^{\prime \prime}$ West) of Lake Champlain, which straddles the Canada - United States border (Supplemental Information, Fig. SD-I1). The characteristics of tributaries are as described by Medalie et al. (2012) and Adhikari et al. (2010). Missisquoi Bay is a shallow water body with a mean depth of $2.8 \mathrm{~m}$ (Galvez and Levine, 2003). Myer and Gruendling (1979) reported that in areas without rooted aquatic vegetation, the wave base can be deep enough during storms to cause mixing of bottom sediments. It is also the principal source of drinking water for a population of approximately 4100 residents (Statistics Canada, 2006). From 1992 to 2009, total phosphorus seasonal mean concentrations (sampling from June to September) increased in Missisquoi Bay by $72 \%$ (representing an increase of $20 \mu \mathrm{g} / \mathrm{L}$ from an initial seasonal mean concentration of approximately $28 \mu \mathrm{g} / \mathrm{L}$ ). In contrast, total nitrogen seasonal mean concentrations decreased by approximately $25 \%$ (representing a decrease of approximately $0.15 \mathrm{mg} / \mathrm{L}$ from an initial seasonal mean concentration of approximately $0.65 \mathrm{mg} / \mathrm{L}$ ) over the same period, possibly related to a reduction in atmospheric nitrogen deposition (Smeltzer et al., 2012). The reduction of the phosphorus is critical for the health of Missisquoi Bay and has led to a bilateral agreement between the province of Quebec (Canada) and state of Vermont (United States) to take action on reducing phosphorus to an acceptable limit of $25 \mu \mathrm{g} / \mathrm{L}$ (Comité inter-ministériel de concertation sur la Baie Missisquoi., 2003) and to guide related research activities (Adhikari et al., 2010).

\subsection{Field sampling and laboratory analyses}

In 2007, a real-time monitoring program was developed and implemented in Missisquoi Bay using an online multi-probe system from YSI (YSI, Yellow Springs, Ohio) as described by McQuaid et al. (2011). The multi-probe system consists of eight sensors: temperature, depth, conductivity, turbidity, $\mathrm{pH}$, dissolved oxygen, chlorophyll fluorescence (excitation: $470 \mathrm{~nm}$; emission: $680 \mathrm{~nm}$ ) and phycocyanin fluorescence (excitation: $590 \mathrm{~nm}$; emission: $680 \mathrm{~nm}$ ). It was installed to monitor the raw water intake of the drinking water treatment plant on the eastern shore of Missisquoi Bay every hour. Information on additional sampling and laboratory analyses of phycocyanin, chlorophyll, taxonomic counts and nutrients are provided in supplemental information (Section S1).

\subsection{Meteorological data collection and treatment}

Meteorological data were obtained from the weather station in Frelighsburg situated close to Missisquoi Bay. Frelighsburg data (Station name: FRELIGHSBURG; Province: QUEBEC; Latitude: $45.05^{\circ} \mathrm{North}$; Longitude: $-72.86^{\circ} \mathrm{West}$; Altitude: 152.4m; climate identification: 7022579), provided by the National Climate Data and Information Archive (2013), were used to develop the model relating meteorological variables with cyanobacterial biovolume (CBV). Hourly data were available, thus the daily means of wind speed and direction were calculated using the method proposed in Roland (2000). Statistica 9.0 (StatSoft.Inc, Tulsa, OK USA), Matlab (version 7.1.0.246 (R14) Service Pack 3, MathWorks, Inc.) and MS Excel (Microsoft, Redmond, WA, USA) were used for statistical analyses. 


\subsection{Development of a Meteorological Index \\ 2.4.1 Description of the approach}

In order to evaluate the effects of meteorological factors on CB biomass, the development of this simple index is based on similar approach from Yu et al. (2002) for integrating the influence of climate components on rice biomass accumulation. $\mathrm{Yu}$ et al. (2002) proposed using a classical logistic growth model in which the maximum relative growth rate $(\mu)$ is defined as shown in equation (1):

$$
\mu=\mu_{0} \times f(p)
$$

where $\mu_{0}$ is the growth rate when meteorological factors are most favourable for population growth. The function $f(p)$ reflects the meteorological factors being considered and can take on values between 0 and 1 with $f(p)=1$ signifying growth without the constraint of meteorological factors and $f(p)=0$ signalling the end of growth because of completely unfavourable conditions.

However, different from the approach by Yu et al. (2002), in this paper, our focus is on the parameterization of $f(p)$ and the relationship between this index and observed biomass accumulation in Missisquoi Bay to provide a functional index at the drinking water treatment plant and to assess the importance of meteorological factors in driving CB blooms. Yu et al. (2002) integrate $f(p)$ directly into their logistic growth model and use multiple linear regression to fit model parameters for the prediction of biomass growth. Our objective in this study was not to predict the amount of cyanobacterial growth, which would require continuous data on nutrient limitation which are not available and are not typically monitored at high frequency at drinking water treatment plant, but rather to estimate the probability of CB blooms occurrence that can be explained by a series of easily measured meteorological parameters.

The meteorological index does not distinguish between the direct and indirect influences that meteorological conditions play on biomass accumulation and it is not possible to directly distinguish accumulation from growth. However, the primary objective is to determine the probability of bloom occurrence given meteorological conditions influencing their presence at a drinking water treatment plant intake. In this context, our expectation is to develop an approach that can easily integrate meteorological factors into an index to adequately describe both CB growth and accumulation under various environmental conditions.

The meteorological index was developed in three stages:

Stage 1) Meteorological index development: Data collected during the years 2007 and 2008 were used to define functions and calibrate all the parameters. The first two years of the 5 years of data were selected for model calibration because they represented a broad range of bloom conditions. In 2007, there was little accumulation of cyanobacteria at the drinking water intake in contrast to 2008 when intense blooms were observed. Additional data were not used in calibration in order to avoid -over-fitting parameters. The definition of this function $f(p)$ takes into account the physical position of the drinking water intake relative to the wind direction. 
Stage 2) Model validation: Data recorded from 2009 - 2011 (YSI probe and FRELIGHSBURG weather station) were used to confirm the link between the function of factor $f(p)$ on cyanobacteria biovolume (CBV). Similar model parameters found for 2007 and 2008 were used for the validation of the following years (2009 2011).

Stage 3) Logistic regression model development: the logistic regression was developed with five years of data (2007-2011) in order to estimate the probability of CB blooms occurrence given the meteorological conditions included in the $f(p)$ function.

\subsubsection{Selection of Meteorological Parameters for $f(p)$}

The selection of meteorological variables was based upon local considerations (position of drinking water intake) and literature review. Wind direction measured in degrees is not monotonically related to CBV because only a specific range of wind directions can physically have an impact on the drinking water treatment plant based on its location. Even with strong winds, if the wind is moving in the direction away from the plant, $C B$ accumulation at the intake is unlikely. There exists an optimal wind direction that could transport CB towards the plant. Thus, wind direction was included in the model based on physical rather than statistical considerations.

The model used water temperature (as opposed to air temperature) because it more directly represents the environmental conditions experienced by the cyanobacteria. Similar variables (wind speed and direction, and water temperature) were used by Liu et al. (2012b) for the development of a model to estimate the probability of bloom occurrence. The measurements of CBV at the drinking water intake represent $C B$ that are at the bottom of the water column, and thus, lower water temperatures can also be related to the presence of cyanobacteria in the lower depths of the water column because of additional processes not considered in the index model (mixing, cyanobacteria behavior with regards to light intensity, cloud cover, etc.). It has been reported that cyanobacteria move towards the bottom of the water column at night when water temperatures are lower (Walsby et al. 1989). Thus, when cyanobacteria are abundant, the dominant risk factors for a drinking water intake are related more to transport phenomena than to cyanobacterial growth. However, over the course of a season, the temperature becomes important when it falls outside of the optimal range for cyanobacterial growth. The model was constructed such that it would be possible to modify parameters according to local conditions. For example, various water bodies will have different dominant CB species. As such, optimal water temperatures could be adapted according to CB species present. However, this approach remains to be tested for systems other than Lake Champlain.

\subsubsection{Definition of parameter functions for $f(p)$}

Following the selection of the variables, $f(p)$ was defined as follows:

$$
\begin{aligned}
& \mathrm{f}\left(\mathrm{p}_{\mathrm{i}}\right)=\mathrm{g}\left(\mathrm{T}_{\text {Wtemp }}\right) \times \mathrm{g}\left(\mathrm{p}_{\mathrm{i}}\right) \\
& \mathrm{g}\left(\mathrm{p}_{\mathrm{i}}\right)=\mathrm{g}(\text { Wind Speed }) \times \mathrm{g}(\text { Wind direction })
\end{aligned}
$$


where $T_{\text {Wtemp }}$ represents the water temperature as measured by the probe installed at the drinking water intake, $\mathrm{g}\left(\mathrm{T}_{\mathrm{Wtemp}}\right)$ is the function describing the influence of water temperature on CB growth, $\mathrm{p}_{\mathrm{i}}$ is the meteorological parameter and $\mathrm{g}\left(\mathrm{p}_{\mathrm{i}}\right)$ is the function representing the influence of wind speed and wind direction on CB accumulation and growth.

Considering meteorological parameters $\mathrm{X}_{1}, \mathrm{X}_{2}, \mathrm{X}_{3} \ldots \mathrm{X}_{\mathrm{N}}$ for a given time series, the function $\mathrm{g}\left(\mathrm{p}_{\mathrm{i}}\right)$ at a given time can be written in the form of:

$$
\mathrm{g}\left(\mathrm{p}_{\mathrm{i}}\right)=\mathrm{K}(\mathrm{i}) / \mathrm{K}_{\mathrm{MAX}}
$$

with

$$
\begin{aligned}
& \mathrm{K}(\mathrm{i})=\sum\left[\mathrm{F}\left(\mathrm{X}_{1}\right) \times \mathrm{F}\left(\mathrm{X}_{2}\right) \times \mathrm{F}\left(\mathrm{X}_{3}\right) \times \ldots \times \mathrm{F}\left(\mathrm{X}_{\mathrm{N}}\right)\right] \\
& \text { and } \quad \mathrm{K}_{\mathrm{MAX}}=\max (\mathrm{K}(\mathrm{i}))
\end{aligned}
$$

From equation (4) we can see that $g\left(\mathrm{p}_{\mathrm{i}}\right)$ will have a value between 0 and 1 . Hence, the expression for the growth and accumulation rate of $\mathrm{CB}$ integrating meteorological parameters and water temperature is:

$$
\mu=\mu_{0} \times \mathrm{g}\left(\mathrm{T}_{\text {Wtemp }}\right) \times \mathrm{g}\left(\mathrm{p}_{\mathrm{i}}\right)
$$

and $f\left(p_{i}\right)$ is therefore equal to $\mu$.

The procedure for $f(p)$ calculation is provided in Fig. SD-I2.

\section{Function for water temperature}

For conditions where water temperature exhibits a large range of variability, the description of the function $\mathrm{g}\left(\mathrm{T}_{\mathrm{Wtemp}}\right)$ can adopt the following form (Lehman, 1975; USEPA, 1985; Bouarab et al., 2002):

$$
\begin{aligned}
& \mathrm{g}\left(\mathrm{T}_{\mathrm{wtemp}}\right)=\exp \left[-\mathrm{a} \times\left(\frac{\mathrm{T}_{\mathrm{wtemp}}-\mathrm{T}_{\mathrm{opt}}}{\mathrm{T}_{\mathrm{x}}-\mathrm{T}_{\mathrm{opt}}}\right)^{2}\right] \\
& \text { with } \quad \mathrm{T}_{\mathrm{x}}=\left\{\begin{array}{l}
\mathrm{T}_{\min } \text { for less than or equal to } \mathrm{T}_{\mathrm{opt}} \\
\mathrm{T}_{\text {max }} \text { for higher than or equal to } \mathrm{T}_{\mathrm{opt}}
\end{array}\right.
\end{aligned}
$$

$a$ is a dimensionless calibration parameter. This approach takes into account three different levels of water temperature: (1) minimum growth temperature $T_{\min }\left({ }^{\circ} \mathrm{C}\right),(2)$ optimum growth temperature $\mathrm{T}_{\mathrm{opt}}\left({ }^{\circ} \mathrm{C}\right)$ and (3) maximum growth temperature $\mathrm{T}_{\max }$ $\left({ }^{\circ} \mathrm{C}\right)$.

As $T_{\min }<T_{\text {opt }}<T_{\max }$, these temperature levels will define four distinct intervals on which i) negligible growth occurs below $\mathrm{T}_{\min }$ or above $\mathrm{T}_{\max }$; ii) increasing growth occurs from $T_{\min }$ or $T_{\max }$ to $T_{\text {opt }}$; and iii) decreasing growth occurs from $T_{\text {opt }}$ to $T_{\min }$ or to $T_{\max }$ (USEPA, 1985). 
By adjusting parameters, equations 8 and 9 can be applied for the environmental conditions at Missisquoi Bay or other source waters where there is a large variation of temperatures. Based on studies of Mooij et al. (2007), Tang et al. (1997) and Seaburg et al. (1982) minimum, optimal and maximum growth temperature are approximately $0^{\circ} \mathrm{C}, 25^{\circ} \mathrm{C}$ and $35^{\circ} \mathrm{C}$, respectively. These studies have demonstrated that out of this temperature range, the growth is undetectable and that the majority of cyanobacterial species have an optimal growth temperature of $25^{\circ} \mathrm{C}$. Additional information on the cyanobacterial species present in the Bay and their optimal growth temperatures are provided in supplemental information (Table SD-1).

\section{Functions for wind speed and wind direction}

The function describing the effect of wind direction (RDIR) is

$$
\begin{aligned}
& \mathrm{F}(\mathrm{RDIR})=\exp [-\mathrm{a} \times \mathrm{C}] \\
& \mathrm{C}=\frac{\left(\text { Wind }_{\text {dir_X }_{\text {X }}}-\text { Wind }_{\text {dir_opt }}\right)^{2}}{\left(\text { Wind }_{\text {dir_X }_{\_}}-\text {Wind }_{\text {dir_Min }}\right)\left(\text { Wind }_{\text {dir_Max }}-\text { Wind }_{\text {dir_X }_{-}}\right)}
\end{aligned}
$$

where Wind dir_ $_{x}$ is the wind direction $\left(^{\circ}\right)$, Wind dir_Min and Wind dir_Max $_{\text {are }}$ its minimal and maximal values, Wind $d_{\text {diropt }}$ is its optimal value for CB accumulation, and $a$ is a dimensionless calibration parameter.

The forms of equations 10 and 11 are similar those of equations 8 and 9 . Similar to water temperature, wind direction is expected to have an optimal value in relation to the position of the drinking water treatment plant intake (the treatment plant is situated in the north-east region of the bay, at around 30 degrees). A similar procedure is used for describing the effect of wind speed.

The function describing the effect of wind speed (RWND) is defined as

$$
\begin{aligned}
& \mathrm{F}(\mathrm{RWND})=\exp [-\mathrm{a} \times \mathrm{B}] \\
& \left.\left(\mathrm{Wind}_{\text {speed_X }}-\mathrm{Wind}_{\text {speed_X }}-\mathrm{Wind}_{\text {speed_Min }}\right)\left(\mathrm{Wind}_{\text {speed_Max }}\right)^{2}-\mathrm{Wind}_{\text {speed_X }}\right)
\end{aligned}
$$

where Wind $_{\text {speed_x } x}$ is the wind speed $(\mathrm{m} / \mathrm{s})$, Wind speed_Min $_{\text {and }}$ Wind speed_Max $_{\text {s. }}$

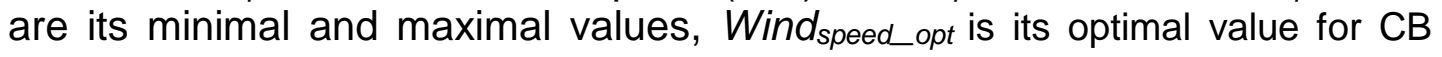
accumulation, and $a$ is a dimensionless calibration parameter.

Weak or intense hydrodynamic fluctuations influence cyanobacteria $\mathrm{Wu}$ et al. 2013). Additional information on the influence of wind speed on cyanobacterial drift for the parameterization of the model is provided in supplemental information (Section S2). Based on the reported values in the literature, model calibration was performed to obtain the appropriate values for wind speed (Table 1). 
Table 1: Calibrated Parameters values for 2007 and 2008

\begin{tabular}{|c|c|c|c|c|}
\hline \multirow{2}{*}{$\begin{array}{c}\text { Model } \\
\text { parameters }\end{array}$} & \multicolumn{4}{|c|}{ Calibrated Parameters } \\
\cline { 2 - 5 } & a & Minimum & Optimum & Maximum \\
\hline Wind direction $\left({ }^{\circ}\right)$ & 7 & 190 & 200 & 310 \\
\hline Wind speed $(\mathrm{m} / \mathrm{s})$ & 0,1 & 2 & 3 & 6 \\
\hline Temperature $\left({ }^{\circ} \mathrm{C}\right)$ & 7 & 10 & 20 & 35 \\
\hline
\end{tabular}

Equations 8,11 , and 13 rely on optimal ranges for the various variables. If measured values of a given factor fall outside of its optimal range, the index would predict no risk to the drinking water intake. For example, if wind speed were too low, minimal transport of CB towards an intake would occur. Thus, when variables fall outside of their optimal ranges, the risk that CB would be present at an intake is expected to be low and controlled by other factors not considered in the index such as light intensity, nutrients, and the vertical movement of $\mathrm{CB}$ in the water column.Model parameters were calibrated with data for 2007 and 2008 and were used for validation with data for 2009, 2010 and 2011. Logistic regression was performed on all data (2007 to 2011) in order to evaluate the probability that a CB bloom occurs at the drinking water intake in relation to the $f(p)$ factor.

\section{Results and Discussion}

\subsection{Meteorological parameters and cyanobacterial biovolume: model parameters}

In this paper, our hypothesis is that exogenous factors dominate and drive the appearance of CB blooms at a drinking water intake where nutrients are not limiting. A simple model was proposed to evaluate easily monitored exogenous variables on CB blooms occurrence in a water body via a meteorological index which assembles different weather variables into a unique index. This study proposes a simple, novel, but highly applicable index approach to evaluate drinking water intake exposure to cyanobacterial bloom occurrences due to their position in the water body.

As described in Section 2.4, the years 2007 and 2008 were used for calibration in order to determine the best values for the minimum, maximum and optimum values of water temperature, wind speed and direction and the factor ' $a$ ' to include in equations 8 to 12. A low value of $f(p)$ was expected for most of 2007 when CB blooms were not observed at the drinking water intake (CBV $\left.<1 \mathrm{~mm}^{3} / \mathrm{L}\right)$, in contrast to 2008 when many CB blooms were observed. Detailed data with regards to taxonomic counts for 2007 and 2008 are available in McQuaid et al. (2011). Approximately $98 \%$ of the CBV in 2007 and 2008 consisted of various species of Microcystis and Anabaena. The year 2007 was an exceptional year for Missisquoi Bay because no CB blooms had been observed until September (Fortin et al., 2010) and no CB were present in large densities at the drinking water intake situated on the north-east side of the Bay. The probe was installed in the north-eastern region 


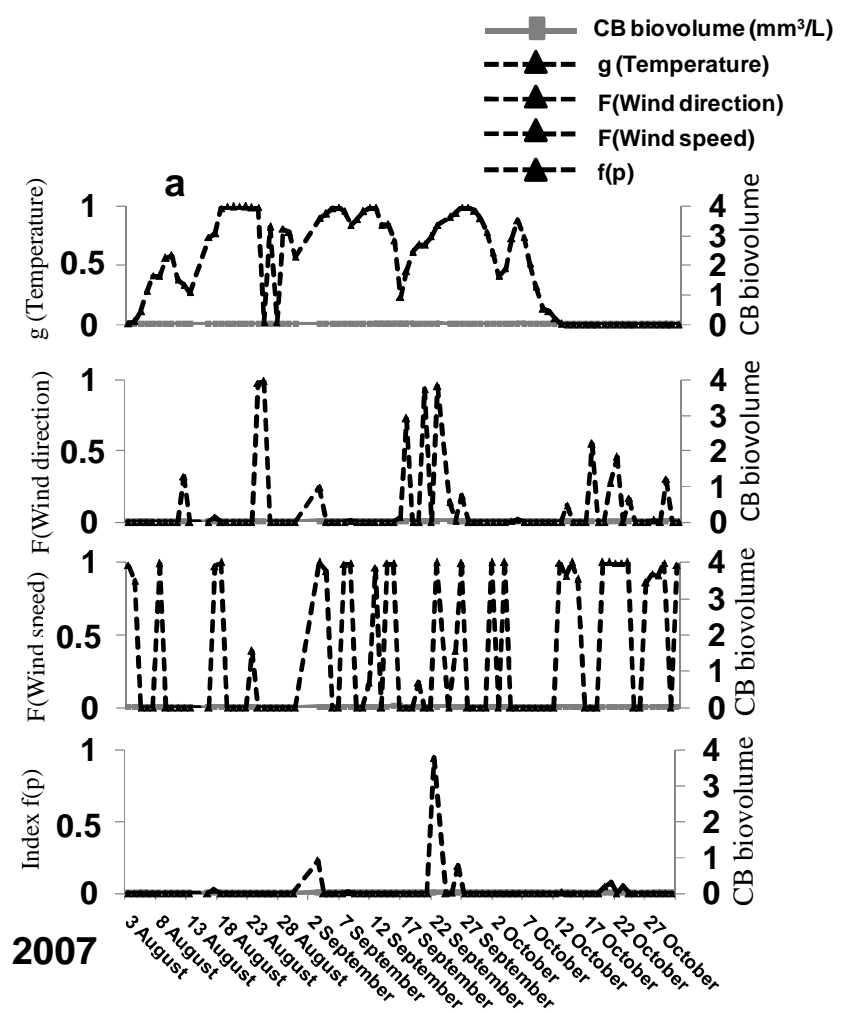

b
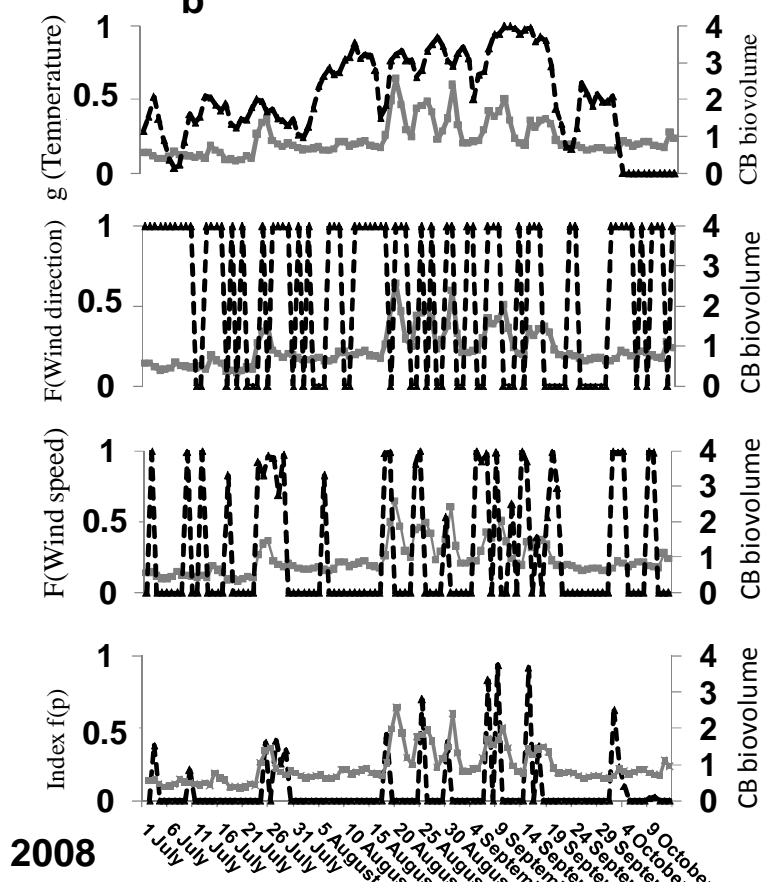

Fig.1: Functions defined from weather parameter versus CBV (model development): a) for 2007 and b) for 2008 
of the study site, thus even if a bloom occurred in Missisquoi Bay, the risk to the north-eastern region, where the probe was installed was low. The wind direction was such that $C B$ would be transported to the outlet (south-western side of the bay) when $\mathrm{CB}$ blooms occurred and wind from the north and east were dominant. This flushing phenomenon observed in many lakes (Dillon, 1975) was dominant during the entire monitored period of 2007. In contrast, in summer 2008, the factor $f(p)$ increased during (or one day prior) to high CBV values. The relationship of the meteorological factor $f(p)$ with CBV at the drinking water intake is shown in Fig. 1a and b. It should be noted that CBV values below the threshold of $1 \mathrm{~mm}^{3} / \mathrm{L}$ represent low concentrations of $\mathrm{CB}$ and thus can be considered as periods of low risk to the drinking water treatment plant despite greater uncertainty with regards to their exact concentrations (McQuaid et al. 2011). The evolution of all the three functions calculated (for water temperature, wind speed and direction) was compared with CBV in order to observe the influence of each meteorological parameter (Fig. 1a and $b$ ). The relative importance of the factors was not considered in the analysis and all factors were given equal weighting. No single function could explain a CBV, but through $f(p)$, all of these variables demonstrated an effect on the variation of CBV at the drinking water intake.

Few explanations have previously been available with regards to the non-existence of $\mathrm{CB}$ blooms observed during the summer 2007 at the drinking water intake at Missisquoi Bay. Based on this study, we can propose as an explanation that, for 2007 the value of $f(p)$ which was very low except for a few days, clearly demonstrated that 2007 had meteorological conditions that were not conducive for CB growth or accumulation near the drinking water intake. This supports our theoretical model of the importance of wind (speed and direction) and water temperature as explained in supplemental information (Section S2 and S3).

Given that 2007 was not conducive for CB growth or accumulation, it is interesting to note that the flushing effect could also have prevented large blooms from forming, dying, settling to the bottom sediments and releasing additional nutrients that would have become available to create a new cycle of CB blooms. Redox conditions in the sediments (Pant and Reddy, 2001) for 2007 at Missisquoi Bay showed that anaerobic conditions did not occur as is typical for other years when large cyanobacterial blooms occur (Smith et al. 2011). Through the use of a combination of different variables in one index $(f(p))$, it is possible to improve explanations of environmental conditions that contribute to CB bloom occurrences. This has been highlighted by other studies using statistical methods to explain CB bloom occurrence (Hu et al., 2009; Liu et al., 2012b).

The investigating results demonstrated that the effects of wind and water temperature cannot be ignored with regards to CB bloom occurrence at any considered position in the water body as the spatial distribution of $\mathrm{CB}$ is affected by wind direction and speed and water temperature (Kanoshina et al. 2003). The importance of wind has been emphasized by Izydorczyk et al. (2005) although they did not quantitatively demonstrate the wind effect on cyanobacteria. The wind speed can induce mixing in the water column and influence nutrient availability (e.g. Maclntyre et al., 1999; Livingstone, 2003; O’Reilly et al., 2003; Schmittner, 2005). 


\subsection{Meteorological parameters and cyanobacterial biovolume: Model application}

Model application for 2009, 2010 and 2011 show a similar trend between $f(p)$ and CBV. As seen in Fig. $2 a, b$ and $c$, the $f(p)$ index is low but CBV is high in some cases (false negatives). However, the false negatives were frequently related to bloom events that occurred over multiple days when the meteorological index decreased faster than the CBV (returning to a state without a bloom). In other instances, false negatives were likely related to endogenous and exogenous factors optimal for cyanobacterial growth but not considered in the index (e.g. solar radiation, nutrients). The benefit of the current index approach is its potential applicability to cyanobacteria impacted drinking water intakes with data that can be easily and reliably obtained in real time. Thus, drinking water treatment plants can evaluate their vulnerability (the probability of bloom occurrence, a maximum probability occurs with a maximum $f(p))$ using meteorological conditions and water temperature without the need to wait for satellite imagery.
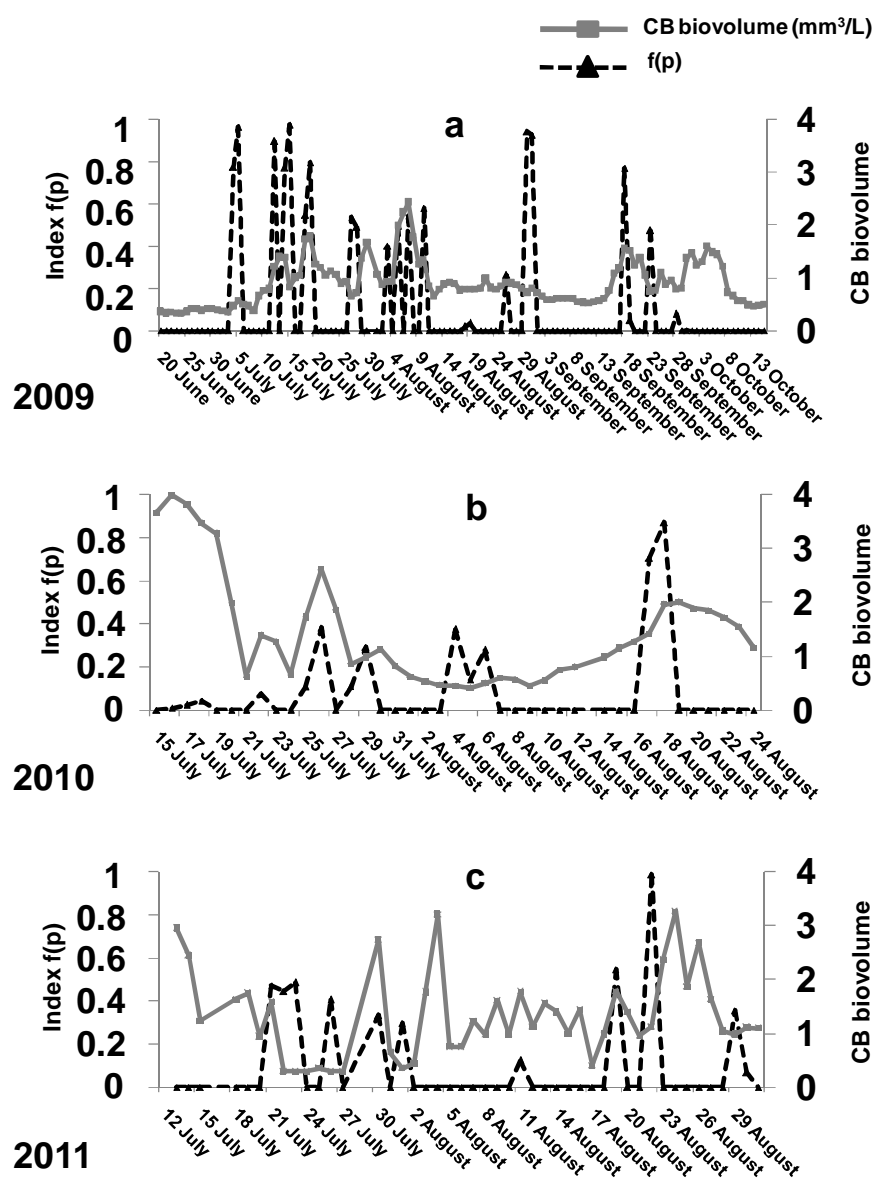

Fig.2: Meteorological parameter $f(p)$ versus CBV (model application): a) for 2009, for b) for 2010 and c) for 2011 


\subsection{Logistic model: Relationship between $f(p)$ and cyanobacterial bloom occurrence}

CB occurrence is a complex phenomenon due to the non-linearity of the variables, as described previously. Thus, a logistic regression model was used to estimate the probability of CB bloom occurrence given by the calculated index $(f(p))$. In order to develop a logistic regression model, a CBV of $1 \mathrm{~mm}^{3} / \mathrm{L}$ was considered as a threshold value for when the drinking water treatment intake is at risk. The $1 \mathrm{~mm}^{3} / \mathrm{L}$ is a locally adapted threshold value and was proposed as the monitoring threshold (alert level) for Missisquoi Bay by McQuaid et al. (2011). McQuaid et al. (2011) found that $1 \mathrm{~mm}^{3} / \mathrm{L}$ corresponded to a maximum potential microcystin concentration of $13 \mu \mathrm{g} / \mathrm{L}$ in Missisquoi Bay. The McQuaid et al. (2011) threshold falls between alert level 1 (biovolume: $0.2 \mathrm{~mm}^{3} / \mathrm{L}$; maximum potential microcystin concentration (MPMC): $2.6 \mu \mathrm{g} / \mathrm{L}$ ) and alert level 2 (biovolume: $10 \mathrm{~mm}^{3} / \mathrm{L}$; MPMC: $130 \mu \mathrm{g} / \mathrm{L}$ ) proposed by Bartram et al. (1999) and also represents the lowest biovolume value for which phycocyanin probes provided reliable estimates in Missisquoi Bay. For CB blooms to develop, it is likely that conditions must be favorable for more than one consecutive day. The logistic model developed was based on $f(p)$ and CBV data from the five years (2007 to 2011). All the parameters values of the model are significant with $p$-value equal to 0.006 with an odds ratio of 6.03 (Table 2).

Table 2: logistic regression between cyanobacterial occurrence bloom and $f(p)$ during the five years (2007 to 2011) $\left(t=\log \left(\frac{P}{1-P}\right) ; P=\right.$ probability of occurrence)

\begin{tabular}{|l|l|l|l|l|l|}
\hline Year & Model Equation & $p$-value & $\begin{array}{l}\text { Odds } \\
\text { ratio }\end{array}$ & $\begin{array}{l}\text { Wald's } \\
\text { Chi- } \\
\text { square }\end{array}$ & $\begin{array}{l}\text { Weather } \\
\text { datas } \\
\text { sources }\end{array}$ \\
\hline $\begin{array}{l}2007 \text { to } \\
2011\end{array}$ & $t=-0.018+1.845 \times f(p)$ & $\begin{array}{l}0.006 \\
(n=393)\end{array}$ & 6.03 & 11.76 & $\begin{array}{l}\text { Freligsburg } \\
\text { weather } \\
\text { station }\end{array}$ \\
\hline
\end{tabular}

As expected, meteorological conditions were observed to have a large influence on CBV increases at the drinking water intake. The odds ratio found for a logistic regression model demonstrated a significant relationship between $f(p)$ and the probability of CB occurrence above the CBV threshold of $1 \mathrm{~mm}^{3} / \mathrm{L}$. Thus, increasing values for $f(p)$ coincide with $C B$ blooms at the drinking water intake. As seen in Fig.3, a maximum probability of $68 \%$ of CB bloom occurrence can be explained by the increase of $f(p)$. An $f(p)$ value of 1 means that the combined effects of wind speed and direction, and water temperature are optimal for CB accumulation at the drinking water intake. It is also interesting to note that at low $f(p)$ values, there is a low probability (less than 26\%) of a CB bloom at the intake. Thus, the probability of a false negative is less than $26 \%$. As described in Section 3.2, false negatives were related to the index decreasing faster than the $\mathrm{CBV}$, and both false positives and 
negatives also arose potentially from the exclusion of factors such as light intensity and nutrients from the index.

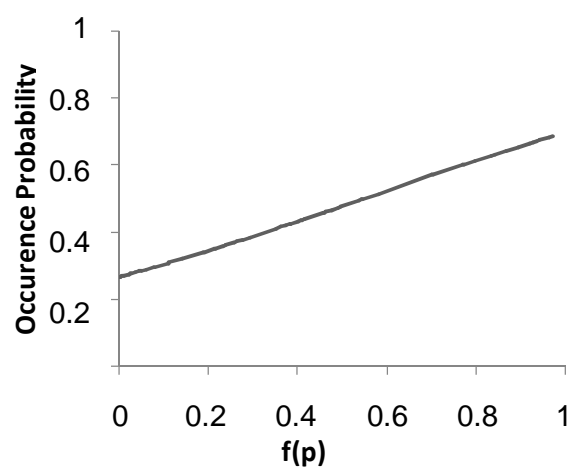

Fig.3: CB blooms occurrence probability versus meteorological factor $f(p)$

Our index approach can be discussed within the context of other statistical approaches that have included regression models (Smith, 1985; Smith et al. 1987), correlations (Varis, 1991), classification and regression trees (Hu et al., 2009), artificial neural networks (Teles et al. 2006; Wei et al. 2001; Maier et al. 1998; Recknagel et al. 1997), and conditional probabilities (Peretyatko et al. 2010). For many statistical approaches it is not possible to distinguish factors that are drivers of CB blooms from those that are merely correlated with CB blooms. For example, although $\mathrm{pH}$ is typically correlated with $\mathrm{CBV}$ and has often been included in regression models, it cannot be predictive because changes in $\mathrm{pH}$ are driven by changes in CBV (Zamyadi et al. 2012b). By studying the probability of CBV conditioned on environmental factors (not including history of CBV), Peretyatko et al. (2010) reached a maximum probability of 0.5 . In addition, some of the environmental factors, such as $\mathrm{pH}$, were not drivers of $\mathrm{CB}$ blooms. In contrast, our index approach found a maximum probability of 0.68 with the maximum index value using only variables that can be viewed as potential drivers of $C B$ accumulation at a drinking water intake. Thus, the index approach provides a robust estimate of the potential for $\mathrm{CB}$ accumulation at a drinking water intake without relying on variables that cannot be monitored continuously, or that are correlated with $C B$ because the $\mathrm{CB}$ themselves were the drivers of the change. Although artificial neural networks and classification and regression trees are powerful techniques for highly non-linear problems, they are black box approaches that do not necessarily encode the available physical knowledge of the system. Using the index approach, we were able to include information and factors based on the physical environment (e.g., the specific location of the drinking water intake) to obtain reliable results for operational decision-making at drinking water treatment plants.

For our model based on the assumption that nutrients are not limiting for $C B$, a better estimate is not expected given that only limited meteorological variables were 
considered and major endogenous factors related to growth like nutrients were not included in the model. The unexplained part of CB occurrence is related to endogenous factors such as nutrient availability and limitation. Thus, we explored the use of a nutrient mass ratio that could be used to augment continuous phycocyanin monitoring at the drinking water intake. CB abundance was compared to the DIN/TP mass ratio. Total, rather than soluble reactive phosphorus was used in the ratio because the algae and cyanobacteria population can store sufficient phosphate to increase 10 -fold, even if no dissolved phosphate can be detected (Chorus and Cavalieri, 2000). The mass ratio DIN/TP provides additional information on nutrient limitation that will impact cyanobacterial growth (Bergstrom, 2010; Ptacnik et al. 2010). We found a significant negative correlation between mass ratio DIN/TP and extracted CB phycocyanin pigment $\left(r^{2}=-0.48, p\right.$-value < 0.05). This correlation suggests that $C B$ abundance is likely to be limited by either the DIN or TP. Two hypotheses are proposed 1) CB dominate under nitrogen limitation due to their efficiency to use trace levels of $D I N$, and 2) CB are more competitive for phosphorus than other algal species as CB are efficient at nutrient uptake and storage (Sorokin and Dallocchio, 2008). Low heterocytes in Missisquoi Bay during summer bloom periods suggests that nitrogen fixing cyanobacteria do not rely on atmospheric $\mathrm{N}_{2}$ (McCarthy et al., 2013). Fig.4 shows the nutrient mass ratio, DIN/TP, from weekly duplicate samples in 2011 from all sites described in Supplemental Information (Figure S1) and its correlation with CB phycocyanin pigment.

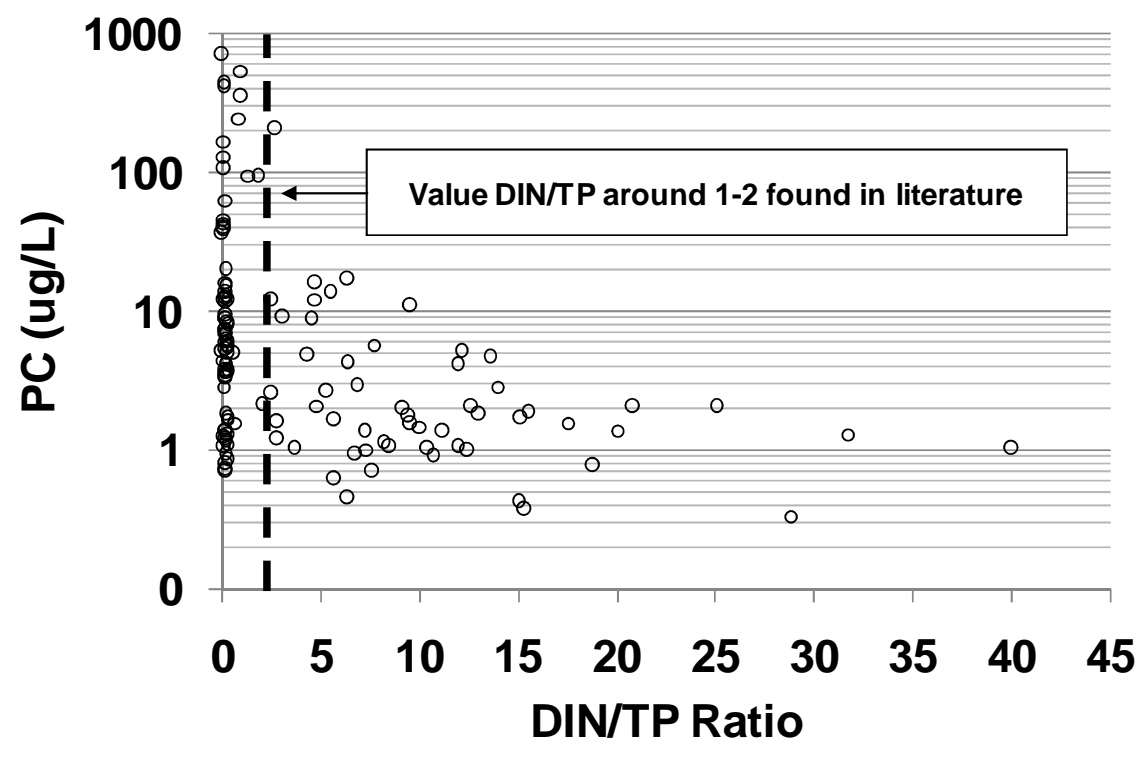

Fig.4: Changes in the mass ratio of dissolved inorganic nitrogen (DIN) to total phosphorus (TP) concentration, and cyanobacteria phycocyanin (PC) concentration Missisquoi Bay in 2011 (mesured in lab) 
It shows that when the mass ratio DIN/TP is low, the phycocyanin concentration, related to $\mathrm{CBV}$, can reach high values. Furthermore, it shows that nutrient limitation does occur and could explain the false positives in the index model. To improve index predictions further, it would be useful to consider the addition of continuous nutrient and light intensity data that were not available in this study. In Fig.4, the critical zone where CB abundance in Missisquoi Bay can be high, is for a DIN/TP mass ratio below 3 and it descends exponentially, similar to values reported between the range of 1-2 by Bergstrom (2010) and Ptacnik et al., (2010). Thus, DIN/TP is potentially a useful indicator of nutrient limitation, although nutrient availability may be driven by phytoplankton dynamics (McCarthy et al., 2013). The critical value of 3 obtained in our study could be used as an additional monitoring index for $\mathrm{CB}$ abundance, albeit not in real time and not necessarily for prediction. However, it could be useful when the meteorological index indicates a high vulnerability to $\mathrm{CB}$ occurrence at the intake.

The meteorological index proposed in this study is most important for determining initial conditions that could lead to a bloom rather than for explaining when the bloom will disappear. This is related to practical considerations at the drinking water plant intake with regards to operational decision-making. For example, drinking water treatment plant operators could take samples to determine optimal coagulants and doses (Zamyadi et al., 2013), or they could opt to close their drinking water intake and use stored water should CBV increase rapidly. At the study site, current practice involves the use of phycocyanin monitoring exclusively for assessing onsite CB vulnerability. With the use of real-time phycocyanin monitoring and the meteorological index, the operators would have important information to determine whether or not optimal bloom conditions are occurring or are likely to occur that will enable them to plan and to closely monitor the CBV at the drinking water intake.

Although the demonstration of the approach was conducted at Missisquoi Bay, this index approach for surface waters other than Lake Champlain could be applied and validated using locally adapted threshold values and variables. The different variables used to calculate this index can easily be collected for any water body affected by $\mathrm{CB}$ and used to evaluate the risk of $\mathrm{CB}$ blooms affecting a zone of interest. Findings from the meteorological index model in our research strongly reinforce our further investigation on a coupled hydrodynamic-cyanobacterial growth model to fully consider meteorological variables and their influence on lake hydrodynamics and cyanobacterial transport.

\section{Conclusions}

An early warning system for drinking water treatment plants should consider meteorological factors in addition to in vivo phycocyanin monitoring in order to adequately respond to $\mathrm{CB}$ events. Wind (speed and direction) and water temperature are related to $\mathrm{CB}$ blooms, both directly with regards to accumulation near a drinking water intake and indirectly on factors related to CB growth. This study shows that all the variables have an effect on CBV at drinking water intake and must be analysed together to understand their effect on CBV at drinking water 
intakes. As nutrient limitation is related to CB occurrence, the DIN/TP mass ratio could be monitored in conjunction with phycocyanin and meteorological variables.

Favourable meteorological conditions (high $f(p)$ value) was related to maximum probability of $68 \%$ that a bloom event with CBV exceeding $1 \mathrm{~mm}^{3} / \mathrm{L}$ would occur. As $\mathrm{CB}$ occurrence at drinking water treatment intakes are largely driven by exogenous factors, the use of hydrodynamic models could be used to more accurately predict $\mathrm{CB}$ events at drinking water intakes and to propose solutions to avoid breakthrough of cyanobacteria into drinking water treatment plants.

\section{Acknowledgments}

This study has been financially support by Engineering Research Council of Canada (NSERC), Canada Foundation for Innovation (CFI) , Fonds de Recherche du Québec - Nature et Technologies (FRQNT), Canada Research Chairs (CRC), Canadian International Development Agency (CIDA). The authors acknowledge the support of Yves Fontaine, Julie Philibert, Jacinthe Mailly and the operators of drinking water treatment plant at Missisquoi Bay for their technical help.

\section{References}

Adhikari, K.B., Madramootoo, A.C., Sarangi, A., (2010). Temporal variability of phosphorus flux from Pike River watershed to the Missisquoi Bay of Quebec. Current Science, 98(1), 58-65.

Bartram J., Chorus I. (1999). Toxic cyanobacteria in Water: A guide to their public health consequences, monitoring and management. London: WHO.

Bartram J., Burch. M., Falconer I. R., Jones G., Kuiper-Goodman T., Chapter 6. Situation Assessment, Planning and Management, in Toxic Cyanobacteria in Water, 1999, pp. 183-210, ed. I. Chorus, and J. Bartram, E \& FN Spon, London, UK.

Bergstrom A.K., (2010). The use of TN:TP and DIN:TP ratios as indicators for phytoplankton nutrient limitation in oligotrophic lakes affected by N deposition. Aquatic Sciences, 72(3), 277-281

Bormans, M., Ford, W.P., Fabbro, L., (2005). Spatial and temporal variability in cyanobacterial populations controlled by physical processes. Journal of Plankton Research, 27(1), 61-70.

Bouarab, M.L., Dauta A., (2002). Croissance en autotrophie et en mixotrophie de la microalgue Micractinium pusillum Fres. isolée d'un lagunage naturel : influence de la lumière et de la température. Revue des Sciences de l'Eau, 15(1), 73-86.

Cao, S.H., Kong, X.F., Luo, C.L., Shi, L.X., Yang, Z., Tao, Y., (2006). Effects of Wind and WindInduced Waves on Vertical Phytoplankton Distribution and Surface Blooms of Microcystis aeruginosa in Lake Taihu. Journal of Freshwater Ecology, 21(2), 231-238.

Chorus, I. and Cavalieri, M. (2000). Cyanobacteria and Algae: Monitoring Bathing Waters - A Practical Guide to the Design and Implementation of Assessments and Monitoring Programmes: WHO.

Christian, E.W., Steinberg, W., Hartmann, M.H., (1988). Planktonic bloom-forming cyanobacteria and the eutrophication of lakes and rivers. Freshwater Biology, 20(2), 279-287.

Comité interministériel de concertation sur la Baie Missisquoi. (2003). Plan d'action 2003-2009 sur la réduction du phosphore, Baie Missisquoi. Région Montérégie.

Cuypers, Y., Vincon-Leite B., Groleau A., Tassin B., and Humbert J. F., (2011), Impact of internal waves on the spatial distribution of Planktothrix rubescens (cyanobacteria) in an alpine lake, ISME J., 5(4), 580-589,

Dillon, J., 1975. The phosphorus budget of Cameron Lake, Ontario: The importance of flushing rate to the degree of eutrophy of lakes. Limnology and Oceanography, 20(1), 28-39.

Elliott, A.J., (2012). Is the future blue-green? A review of the current model predictions of how climate change could affect pelagic freshwater cyanobacteria. Water Research, 46(5), 1364-1371.

Falconer, I., 2005, Cyanobacterial toxins of drinking water supplies-Cylindrospermopsins and microcystins: Boca Raton, Florida, CRC Press, 279 p. 
Falconer, I., Bartram, J., Chorus I., Kuiper-Goodman, T., Utkilen, H., Burch, M., Codd A.G., (1999). Safe levels and safe practices. In: Chorus I and Bartram J (eds). Toxic cyanobacteria in Water. E \& FN Spon: New York, USA, pp 156-178.

Ferber, L. R., Levine S. N.,Lini A., Livingston G. P., 2004. Do cyanobacteria dominate in eutrophic lakes because they fix atmospheric nitrogen? Freshwater Biology, 49(6). 690-708

Fortin N., Rodriguez R. A., Jing H., Pick F., Bird D., Greer C. W., 2010. Detection of microcystinproducing cyanobacteria in Missisquoi Bay, Quebec, Canada, using quantitative PCR. Applied Environmental Microbiology, 76(5), 5105-5112

Galvez R., Levine S., (2003). Canada-USA Agreement on the Eutrophication Control and Protection of Lake Champlain Quebec, Laval University, Quebec, Canada and Prof. Rubenstein School U. of Vermont, Burlington, VT, USA, p. 4.

Havens K.E.,James R.T.,East T.L., Smith V. H., (2003). N:P ratios, light limitation, and cyanobacterial dominance in a subtropical lake impacted by non-point source nutrient pollution. Environmental Pollution, 122(3), 379-390.

Howard A., (1994). "Problem cyanobacteria blooms: Explanation and simulation modeling", Transactions Institute of British Geographers, 19(2), 213-224

Hu, W., Connell, D., Mengersen, K., Tong, S., (2009). Weather Variability, Sunspots, and the Blooms of Cyanobacteria. EcoHealth, 6(1), 71-78.

Izydorczyk, K., Tarczynska M., Jurczak, T., Mrowczynski, J., Zalewski, M., (2005). Measurement of phycocyanin fluorescence as an online early warning system for cyanobacteria in reservoir intake water. Environmental Toxicology, 20(4), 425-430.

Jayatissa, L.P., Silva, E.I.L., McElhiney, J., Lawton L.A., (2006). Occurrence of toxigenic cyanobacterial blooms in freshwaters of Sri Lanka. System Applied Microbiology, 29(2), 156-164.

Kanoshina, I., Lips, U., Leppanen, M.J., (2003). The influence of weather conditions (temperature and wind) on cyanobacterial bloom development in the Gulf of Finland (Baltic Sea). Harmful Algae, 2(1), 29-41

Lemmin U., Mortimer C. H. (1986). Test of an extension to internal seiches of Defant's procedure for determination of surface seiche characteristics in real lakes. Limnology and Oceanography, 31(6), 1207-1231.

Lehman, J.T., Botkin, D.B., Likens, G.E., (1975). The assumptions and rationales of a computer model of phytoplankton population dynamics. Limnology, 20(3), 343-364.

Le Vu B., Vinçon-Leite B., Lemaire B. J., Bensoussan N., Calzas M., Drezen C., Deroubaix J. F., Escoffier N., Dégrés Y., Freissinet C., Groleau A., Humbert J.F., Paolini G., Prévot F., Quiblier C., Rioust E., Tassin B. (2010). High-frequency monitoring of phytoplankton dynamics within the European water framework directive: application to metalimnetic cyanobacteria. Biogeochemistry, 106(2), 229-242,

Lilover M.J, Stips, A., (2008). The variability of parameters controlling the cyanobacteria bloom biomass in the baltic Sea. Journal of Marine System, 74, Supplement, S108-S115

Liu, L., Liu, D., Johnson, D., Yi, Z., Huang, Y., (2012a). Effects of vertical mixing on phytoplankton blooms in Xiangxi Bay of Three Gorges Reservoir: Implications for management. Water Research, 46(5), 2121-2130.

Liu, Y., Wang, Z., Guo, H., Yu S., Sheng H., (2012b). Modelling the Effect of Weather Conditions on Cyanobacterial Bloom Outbreaks in Lake Dianchi: a Rough Decision-Adjusted Logistic Regression Model. Environmental Modeling and Assessment, 46(5), 2121-2130.

Livingstone D.M., (2003). Impact of secular climate change on the thermal structure of a large temperate central European lake. Climatic Change, 57(1-2), 205-225

Maclntyre, S., Flynn, K.M., Jellison, R., Romero, J.R. (1999). Boundary Mixing and Nutrient Fluxes in Mono Lake, California. Limnology and Oceanography, 44(3), 512-529.

Maier, H.R., Dandy, G.C., Burch, M.D., 1998. Use of artificial neural networks for modelling cyanobacteria Anabaena spp. in the River Murray, South Australia. Ecological. Modelling, 105 (2/3), 257-272.

Marcé R., Feijoo C., Navarro E., Ordonez J., Goma J., Armengol J., (2007). Interaction between windinduced seiches and convective cooling governs algal distribution in a canyon-shaped reservoir. Freshwater Biology, 52(7), 1336-1352.

McCarthy J. M., Gardner S. W., Lehmann F. M., Bird F. D., (2013) Implications of water column ammonium uptake and regeneration for the nitrogen budget in temperate, eutrophic Missisquoi Bay, Lake Champlain (Canada/USA). Hydrobiologia, 718 (1), 173-188 
McQuaid, N., Zamyadi, A., Prevost, M., Bird, D., Dorner S., (2011) Use of in vivo phycocyanin fluorescence to monitor potential microcystin producing cyanobacterial biovolume in a drinking water source. Journal of Environmental Monitoring, 13(2), 455-463.

Medalie, L., Hirsch, M.R., Archfield, A.S., (2012). Use of flow-normalization to evaluate nutrient concentration and flux changes in Lake Champlain tributaries, 1990-2009. Journal of Great Lakes Research, 38(1), 58-67.

Mehnert G., Leunert F., Cires S., Johnk D. K., Rucker J., Nixdorf B., Wiedner C., (2010). Competitiveness of invasive and native cyanobacteria from temperate freshwaters under various light and temperature conditions. Journal of Plankton Research, 32(7), 1009-1021.

Mooij,W., Janse, J.,DeSenerpont Domis, L., Hülsmann, S., Ibelings, B., (2007). Predicting the effect of climate change on temperate shallow lakes with the ecosystem model PCLake. Hydrobiologia, 584(1), 443-454.

Myer, G., Gruendling G.K., (1979). Limnology of Lake Champlain. Lake Champlain Basin Study Report No. LCBS-30, New England River Basin Commission, Burlington,VT.

National Climate Data and Information Archive (2013).http://www.climat.meteo.gc.ca/climateData/. Last Updated Monday, 04 February 2013 by www.climate.weatheroffice.gc.ca

Ostos, M.E., Pizarro, C.L., Basanta, A., George, G.D., (2009). The influence of wind-induced mixing on the vertical distribution of buoyant and sinking phytoplankton species. Aquatic Ecology, 43(2), 271-284

Pant H.K, Reddy K.R. 2001. Phosphorus sorbtion characteristics of estuarine sediments under different redox conditions. Journal of Environmental Qual., 30(4), 1474-1480.

Peretyatko, A., S. Teissier, S. De Backer \& L. Triest, 2010. Assessment of the risk of cyanobacterial bloom occurrence in urban ponds: probabilistic approach. Annales De Limnologie - International Journal of Limnology, 46(2), 121-133.

Ptacnik, R., Andersen, T., Tamminen, T., (2010). Performance of the Redfield Ratio and a Family of Nutrient Limitation Indicators as Thresholds for Phytoplankton N vs. P Limitation. Ecosystems, 13(8), 1201-1214

Recknagel, F., French, M., Harkonen, P., Yabunaka, K.-I., 1997. Artificial neural network approach for modelling and prediction of algal blooms. Ecological Modelling, 96(1-3), 11-28.

Reichwaldt, S.E., Ghadouani, A., (2012). Effects of rainfall patterns on toxic cyanobacterial blooms in a changing climate: Between simplistic scenarios and complex dynamics. Water Research, 46(5), 1372-1393.

Robarts, R. D., Zohary, T., (1987). Temperature effects on photosynthetic capacity, respiration, and growth rates of bloom-forming cyanobacteria. N.Z. Journal of Marine Freshwater Research, 21(3), 391-399.

Roland S. (2000). Meteorology for Scientists and Engineers. SE, Brooks/Cole, Thomson learning, USA.

Schindler, D.W., (1977). Evolution of phosphorus limitation in lakes, Science, Vol. 195, p. 260-262

Schmittner A., (2005). Decline of the marine ecosystem caused by a reduction in the Atlantic overturning circulation. Nature 434(7033), 628-633

Seaburg, G.K., Parked, C.B., Wharton, A.R., Simmons, M.G., (1981). Temperature-growth reponses of algal isolates from Antartic oaes. Journal of Phycology, 17(4), 353-360.

Smeltzer, E., Shambaugh A. D., Stangel P. (2012). Environmental change in Lake Champlain revealed by long-term monitoring. Journal of Great Lakes Research, 38, Supplement 1, 6-18.

Smith, L., Watzin, C. M., Druschel, G. (2011). Relating sediment phosphorus mobility to seasonal and diel redox fluctuations at the sediment-water interface in a eutrophic freshwater lake. Limnology ang Oceanography, 56(6), 2251-2264

Smith, V.H., Willen, B., Karlsson, B., 1987. Predicting the Summer peak biomass of four species of blue-green algae (cyanophyta:cyanobacteria) in Swedish lakes. Water Resour. Bull., 23 (3), 397-402.

Smith V.H., (1986). Light and nutrient effects on the relative biomass of blue green algae in lake phytoplankton. Canadian Journal of Fisheries and Aquatic Sciences, 43(1), 148-153.

Smith, V.H., 1985. Predictive models for the biomass of blue-green algae in lakes. Water Resour. Bull. 21 (3), 433-439.

Sorokin, I.Y., Dallocchio F., (2008). Dynamics of phosphorus in the Venice lagoon during a picocyanobacteria bloom. Journal of Plankton Research, 30(9), 1019-1026.

Statistics Canada, 2006. Community Profiles-Missisquoi Bay Area, Statistics Canada, Government of Canada 
Steffensen, D.A., 2008. Economic cost of cyanobacterial blooms. In: Hudnell, H.K. (Ed.), Cyanobacterial Harmful Algal Blooms: State of the Science and Research Needs. Adv. Exp. Med. Assoc., vol.619 Springer Press, New York, pp. 855-866 http://www.epa.gov/cyano_habs_symposium/. Accessed Nov 09, 2012 (Chapter 37).

Tang P.Y.E., Tremblay R., Vincent F. W., (1997). Cyanobacterial dominance of polar freshwater ecosystems: are high-latitude mat-formers adapted to low temperature. Journal of phycology, 33(2), 171-181.

Teles, L.O., Pereira, E., Saker, M., Vasconcelos, V., 2006. Time series forecasting of cyanobacteria blooms in the Crestuma reservoir (Douro River, Portugal) using artificial neural networks. Journal of Environmental Management. 38(2), 227-237.

Trojanowska A.A., Izydorczyk K., (2010). Phosphorus fractions transformation in sediments before and after cyanobacterial bloom: implications for reduction of eutrophication symptoms in dam reservoir. Water Air Soil Pollution, 211(1-4), 287-298.

United Stated Environnemental Protection Agency (USEPA), (1985). Rates, Constants, and Kinetics Formulations in Surface Water Quality Modeling.

Varis, O., 1991. Associations between lake phytoplankton community and growth factors-a canonical correlation analysis. Hydrobiologia, 210 (3), 209-216.

Vincent, W. F., (1981). Rapid physiological assays for nutrient demand by the plankton. I. Nitrogen. Journal Plankton Research, 3(4), 685-697.

Wagner, C., Adrian, R., (2009). Cyanobacteria dominance: quantifying the effects of climate change. Limnology and Oceanography, 54(2), 2460-2468.

Walsby, A. E., Reynolds, C.S., Oliver, R.L., Kromkamp, J., (1989). The role of gas vacuoles and carbohydrate content in the buoyancy and ertical distribution of Anabaena minutissima in Lake Rotongaio, New Zealand. Archiv für Hydrobiologie-Beiheft Ergebnisse der Limnologie, 32, 1-25.

Wei, B., Sugiura, N., Maekawa, T., 2001. Use of artificial neural network in the prediction of algal blooms. Water Research, 35 (8), 2022-2028.

Wongsai, S., Luo, K., (2007). Understanding environmental factors associated with cyanobacterial bloom. Paper presented at the 3rd IASTED International Conference on Environmental Modelling and Simulation, EMS 2007, Honolulu, HI, United states.

Wu T., Qin B., Zhu G., Luo L., Ding Y., Bian G., (2013). Dynamics of cyanobacterial bloom formation during short-term hydrodynamic fluctuation in a large shallow, eutrophic, and wind-exposed Lake Taihu, China. Environmental Science Pollution Research International, 1-11.

Wynne, T. T., Stumpf R. P., Tomlinson M. C., Fahnensteil G. L., Schwab D. J., Dyble J., Joshi S.. (2013). Evolution of a Cyanobacterial Bloom Forecast System in Western Lake Erie: Development and Initial Evaluation. Journal of Great Lakes Research, 39(1), 90-99.

Yu, Q., Liu, J., Zhang, Y., Li, J., (2002). Simulation of rice biomass accumulation by an extended logistic model including influence of meteorological factors. International Journal of Biometeorology, 46(4), 185-91.

Zamyadi A., Dorner S., Sauvé S., Ellis D., Bolduc A., Bastien C., Prévost M., (2013). Speciesdependence of cyanobacteria removal efficiency by different drinking water treatment processes. Water Research, 47(8), 2689-2700

Zamyadi, A., MacLeod, L. S., Fan, Y., McQuaid, N., Dorner, S., Sauvé, S., Prévost, M., (2012a). Toxic cyanobacterial breakthrough and accumulation in a drinking water plant: A monitoring and treatment challenge. Water Research, 46 (5), 1511-1523.

Zamyadi, A., McQuaid, N., Prevost, M., Dorner S., (2012b). Monitoring of potentially toxic cyanobacteria using an online multi-probe in drinking water sources. Journal of Environmental Monitoring, 14(2), 579-588.

Zhang, M., Duan, H., Shi, X., Yu, Y., Kong, F., (2012). Contributions of meteorology to the phenology of cyanobacterial blooms: Implications for future climate change. Water Research, 46(5), 442452. 